\title{
El centro histórico y el de nuestra propia historia. Sobre el Museo Provincial de León (Alejandro de la Sota)
}

\author{
Luis TEJEDOR FERnÁNDEZ \\ Área de Composición Arquitectónica \\ Escuela Técnica Superior de Arquitectura / Universidad de Málaga \\ luistejedor@coamalaga.es
}

Recibido: 26/06/2012

Modificado: $11 / 11 / 2012$

Aceptado: $15 / 11 / 2012$

\section{Resumen}

Entender el centro histórico de la ciudad como el espacio existencial en el que se depositan sus valores culturales, esencia de sus orígenes, conduce a la mejor arquitectura contemporánea a trasladar sus inquietudes desde la construcción del objeto concreto, a proyectar un vacío en el que la vida siga su curso, preservando el valor cultural de los espacios públicos que median entre los edificios. El proyecto de Alejandro de la Sota para el Museo Provincial de León es un buen ejemplo de esta actitud cultural y urbana.

Palabras clave: centro histórico, espacio existencial, patrimonio, Alejandro de la Sota, centro y cero.

Title: The Historical City Centre and that of Our Own History. About the Provincial Museum in León (Alejandro de la Sota)

\section{Abstract}

Understanding the historical city centre as the existential space in which its cultural values are deposited, essence of its origins, inspires the best contemporary architecture to shift its concerns from building specific objects towards designing an empty space in which life can take its course, preserving the cultural value of public spaces between buildings. Alejandro de la Sota's project for the Provincial Museum in León is a good example of this cultural and urban attitude.

Keywords: historical city centre, existential space, patrimony, Alejandro de la Sota, centre and zero.

\section{Índice}

0 . Introducción

1. Acerca del espacio existencial

2. El hogar, centro de nuestro mundo

3. El patrimonio y sus conflictos asociados

4. El proyecto para el Museo Provincial de León (A. de la Sota)

5. Conclusión

5.1. Coda: Centro y Cero 


\section{Introducción}

El título de este artículo suscita múltiples reflexiones, y nos remite de inmediato a obras que constituyen ejemplos de aproximación, desde la arquitectura, a la construcción del espacio público. Pensando en los conceptos que en él se incluyen -el centro y la Historia-, recordemos dos imágenes bien conocidas:

1) el edificio proyectado por Adolf Loos en la Michaelerplatz de Viena, frente al Palacio Imperial, terminado de construir en 1911 (figura 1).

2) el edificio proyectado por Hans Scharoun para la Filarmónica de Berlín en una fotografía panorámica de 1964 tomada poco después de su finalización, y que nos lo muestra en un entorno urbano que aun refleja la devastación provocada por la II Guerra Mundial (figura 2).

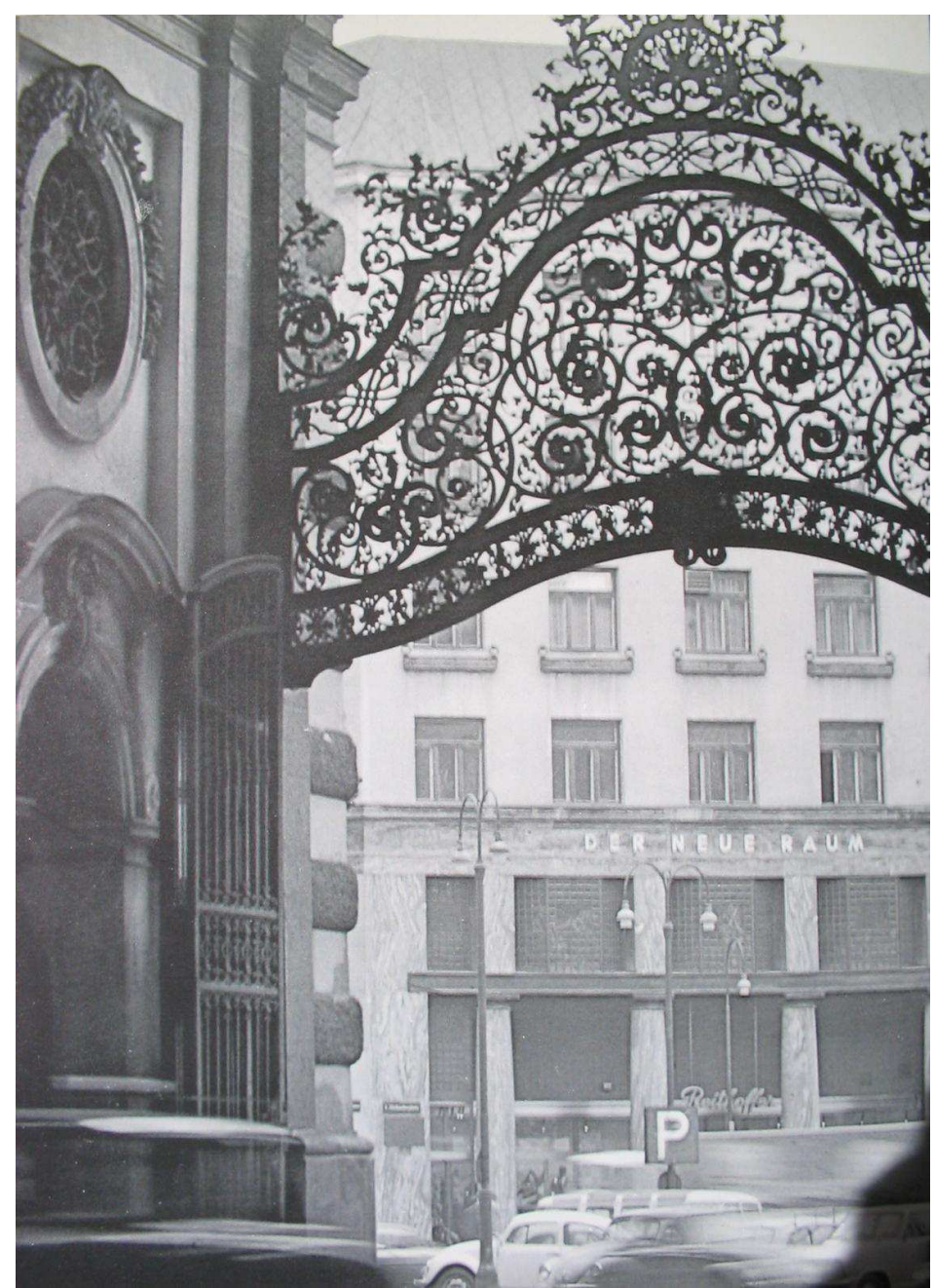

Figura 1. Edificio en la Michaelerplatz de Viena (1911). Arq.: Adolf Loos. 


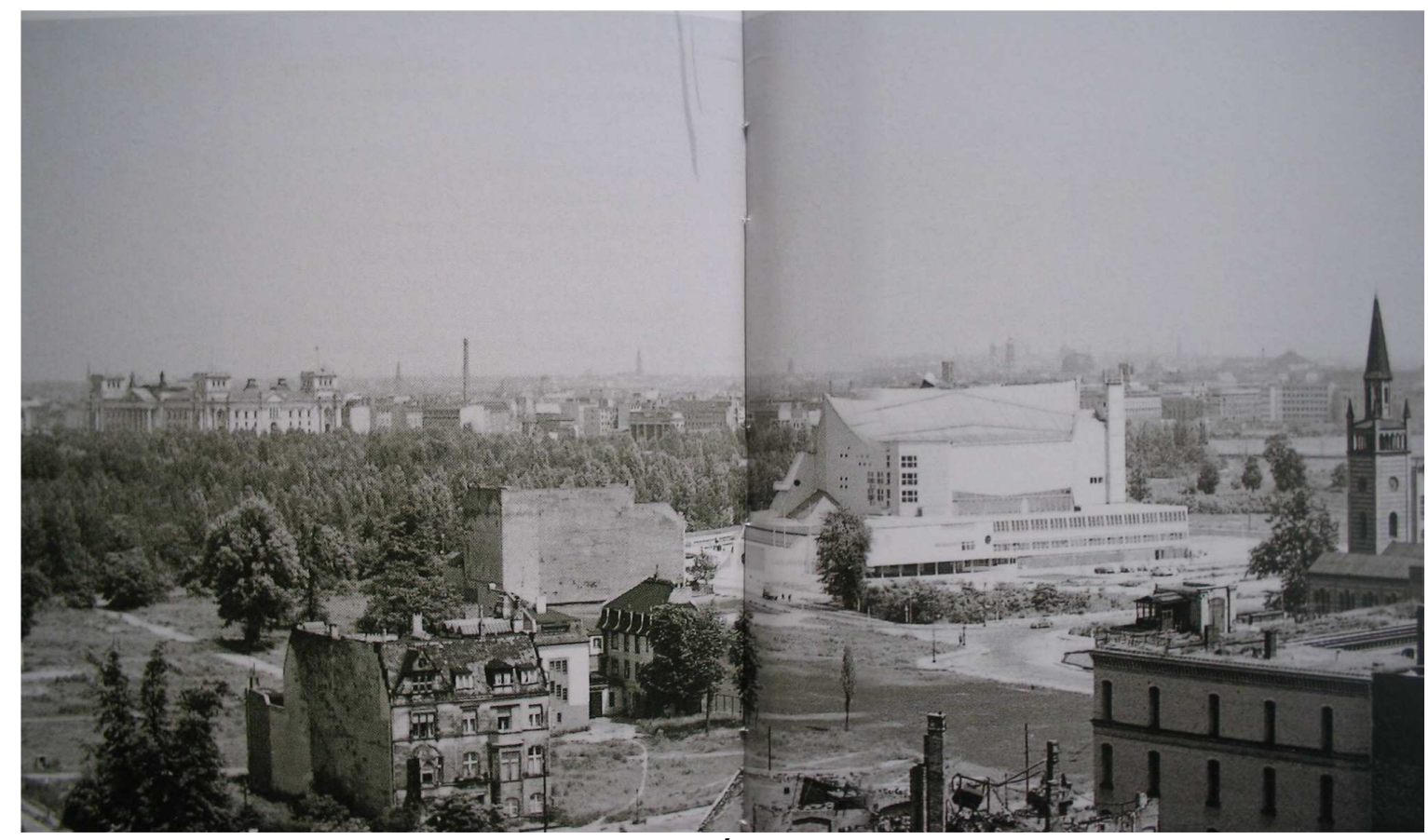

Figura 2. Edificio Philharmonie, Berlín, en 1964. Arq.: Hans Scharoun.

Ambos edificios constituyen sendas intervenciones en los conjuntos urbanos que trascienden los valores disciplinares, expresando una honda reflexión sobre la época, la cultura y la capacidad regeneradora - no solo física, sino también moral- de la arquitectura, a la hora de incidir en la construcción del espacio urbano en el que han de transcurrir y desarrollarse nuestras vidas.

\section{Acerca del espacio existencial}

Vivimos en el espacio, soporte de nuestra existencia. Intuimos que toda actividad humana tiene una imagen espacial asociada, lo cual significa que, admitiendo nuestra vida como una existencia activa, podemos identificar un espacio como propio y personal, un espacio existencial. Este espacio existencial se expande a partir de un centro -nuestro espacio físico asociado-, describe unos recorridos -los adecuados a nuestras actividades- $y$ determina unas zonas 0 circunscripciones. Centros, recorridos y zonas son los elementos que constituyen el espacio existencial.

La percepción del espacio existencial está condicionada por cualidades físicas concretas tales como el color, la textura, la apertura o clausura espacial, o cualquier otra impresión sensorial. Esas cualidades proporcionan al espacio físico su carácter, le otorgan la concreción necesaria para poder identificar ese espacio como un lugar. 


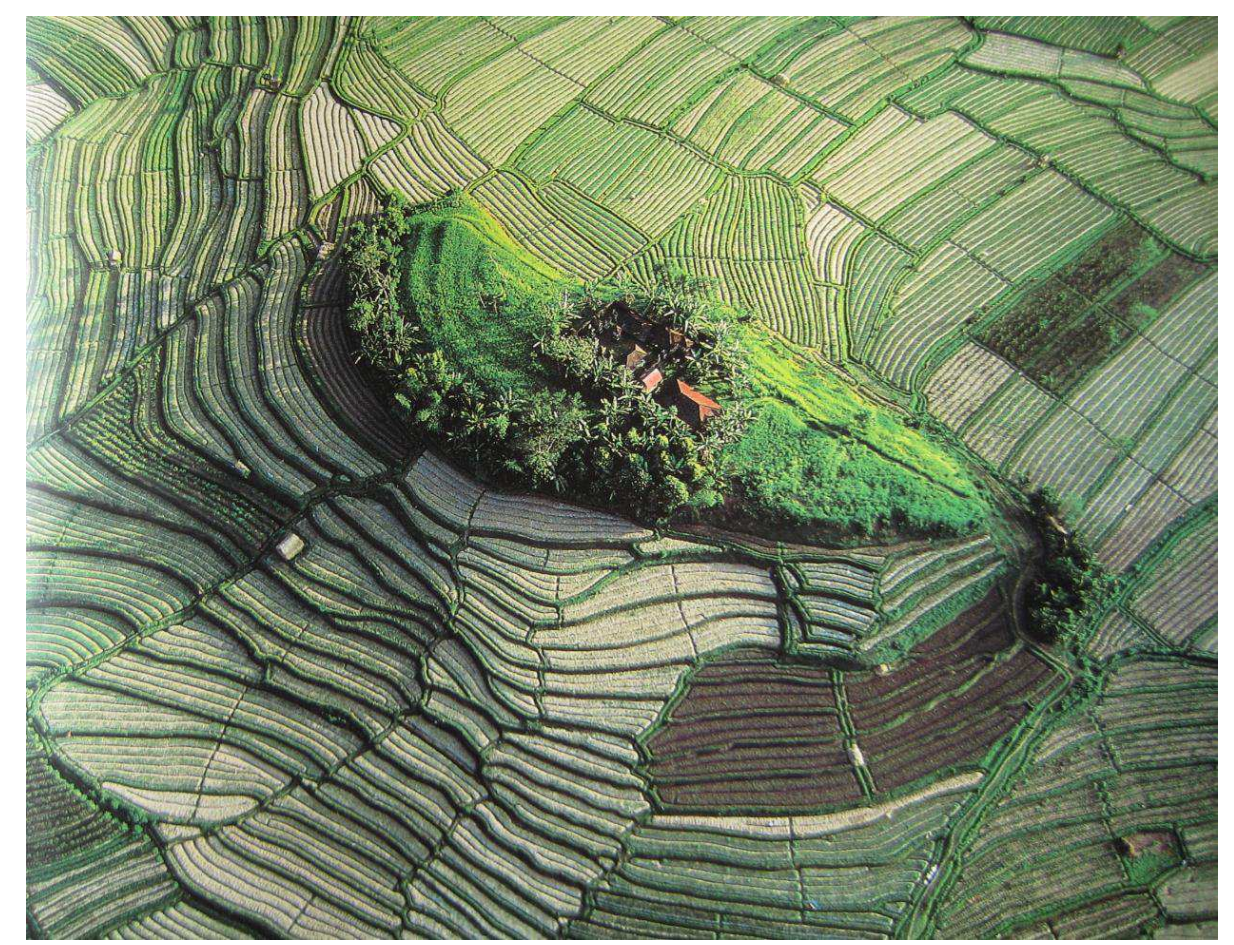

Figura 3. Arrozales en Bali: centro, recorridos, zonas.

La idea de espacio existencial no es excluyente, los elementos que lo integran pueden ser $-y$ son- compartidos por un número indeterminado de individuos. Esto es evidente si nos referimos a los recorridos y las zonas. Pero, dado que el concepto 'espacio existencial' está asociado a cada actividad vital, personal e individual, el espacio que en su constitución ocupa el centro puede ser origen de un cierto conflicto. Ello nos lleva a la siguiente reflexión, que afecta a ese posible conflicto entre intereses públicos y privados a la hora de intentar la conquista del centro.

\section{El hogar, centro de nuestro mundo}

Para Christian Norberg-Schulz (1979: 223-229), si el concepto de Centro del Mundo hace referencia a una meta pública ideal, la palabra hogar posee connotaciones de privacidad, y expresa que la existencia de cada persona tiene su centro. El hogar es el lugar del que partimos y al que regresamos, en nuestra particular 'odisea' diaria y vital. Desde nuestro centro-hogar descubrimos el mundo y a los demás, compartimos otros lugares, enriquecemos nuestra memoria traspasando las fronteras de nuestros espacios existenciales, y regresamos transformados por la experiencia.

Siguiendo este argumento, la actividad de viajar consistiría en la realización de recorridos orientados a la búsqueda y conocimiento de otros espacios, ampliando nuestro horizonte. La memoria de esa experiencia pasa a incorporarse a nuestra vida, a ensanchar nuestro propio espacio. 


\section{El patrimonio y sus conflictos asociados}

Según Italo Calvino, el concepto 'patrimonio' tiene connotaciones económicas, así como culturales ${ }^{1}$. Al contrario que el 'bien cultural', concepto cuyo significado se inscribe más plenamente en un ámbito teórico, aquello que se considera patrimonio posee un valor crematístico, de mercado. El viaje como experiencia cultural personal a la que antes nos hemos referido se patrimonializa dando lugar a una actividad económica que denominamos turismo, actividad que tiende a la explotación de los atractivos implícitos en los lugares, en aquellos espacios dotados de un carácter concreto que los hace únicos. En principio, esta patrimonialización de un lugar no tendría por qué entrar en conflicto con su correcta percepción cultural, aquella que nos enriquece espiritualmente. Sin embargo, tal cosa ocurre con frecuencia, cuando el turismo, como actividad económica dominante, alcanza a alterar el carácter del lugar. El cúmulo de cualidades que configuran dicho carácter se ve reducido a aquellos aspectos que facilitan su consumo inmediato, produciéndose una 'descaracterización' en la que el lugar cede ante su mera imagen. Si la valoración plena del paisaje urbano vinculado a nuestra existencia requiere de la lentitud propia de los ciclos vitales, de la plena maduración de la persona, la valoración turístico-patrimonial de ese paisaje suele estar mediatizada por la premura, por ciclos económicos de mucho más corto recorrido.

Por lo expuesto, cabe preguntarse si el espacio de la ciudadpatrimonio (de la Humanidad, nada menos), puede considerarse ciudad de verdad. Si la actividad turística torna la ciudad en museo, que en su origen tipológico no es sino "[...] un gran almacén de cosas buenísimas que se permite sea visitado. Su existencia es un hecho antinatural: nada ha sido creado para almacenarse" (De la Sota 1989: 190), las actividades tendentes a la patrimonialización de la ciudad para incentivar su atractivo turístico no pueden por menos que tener un cierto cariz forense. Congelar la materia construida y conservar el patrimonio edificado son, con frecuencia, actividades relacionadas, que olvidan la naturaleza cambiante de esa materia orgánica que es $-y$ así ha sido siempre- la ciudad auténtica. Actitud bien diferente a la de construir nuevos espacios -vacíos-, en los que la vida pueda encontrar su lugar.

\footnotetext{
1 "La palabra 'patrimonio', cara al viejo corazón de la Francia balzaciana y ahorrativa, crea la impresión de algo insólito, sustancioso, capitalizable (mientras que los italianos decimos 'bienes culturales', expresión carente de cualquier connotación de concreción y posesión); tal vez sólo el reflejo del interés material puede contrabalancear la tendencia a cumplir el gesto instintivo del hombre contemporáneo: el gesto de arrojar a la basura" (Calvino 1998: 47-52).
} 


\section{El proyecto para el Museo Provincial de León (A. de la Sota)}

Mostraremos a continuación un caso concreto de intervención en el espacio patrimonial que es la ciudad a partir de un proyecto arquitectónico, caracterizado por su voluntad de conceder mayor importancia al valor cultural del espacio urbano transformado por la presencia del edificio, que a su intrínseco valor patrimonial en cuanto objeto construido.

El proyecto para el Museo Provincial de León (1984), del arquitecto Alejandro de la Sota (Pontevedra, 1913-Madrid, 1996), plantea la conversión del Palacio Episcopal de esa ciudad en Museo. En la memoria del proyecto, el autor expresa sus reticencias a los cambios indiscriminados de uso en los edificios para así justificar su conservación a ultranza. También expresa su oposición a las ordenanzas urbanísticas que restringen las posibilidades de intervención en los edificios que, por antiguos, merecen ser protegidos -la identificación, no siempre acertada, de lo antiguo con lo bueno-. Tampoco se muestra muy entusiasmado con la propia existencia de edificios -museos- destinados a almacenar cosas buenísimas que no fueron creadas para ser almacenadas, y que permanecen cerrados parte de las horas del día y todas las de la noche.
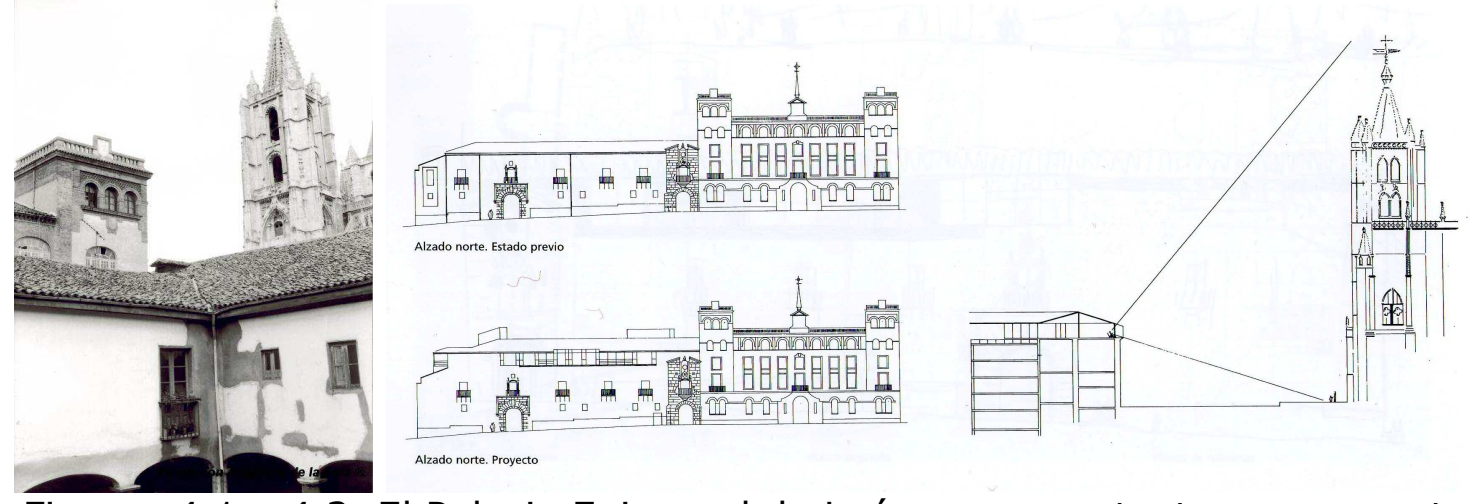

Figuras 4.1 y 4.2. El Palacio Episcopal de León en su contexto, y propuesta de elevación de la última planta con los miradores hacia la Catedral.

Como una especie de 'poeta negativo', Sota conjuga estas aparentes adversidades en un proyecto magistral, que intentó ser un foco de actividad cultural junto a la Catedral, pero que no llegó a construirse por la actitud transgresora con la que el autor desacraliza el valor patrimonial del edificio en el que ha de intervenir. Demoler el patio de columnas del viejo edificio (figura 4.1) para insertar en él el Museo (figuras 5.1 y 5.2), entendido como una 'caja fuerte' accesible a las horas de visita, y visible siempre a través de un gran 'escaparate' (figura 6.3), era mucho más de lo que la ortodoxa Conservación del Patrimonio podía tolerar. También lo era la introducción de la vida urbana en su interior, el intento de reanimar y 
dotar de pulso a una actividad, en principio, tan poco vital como la museística.
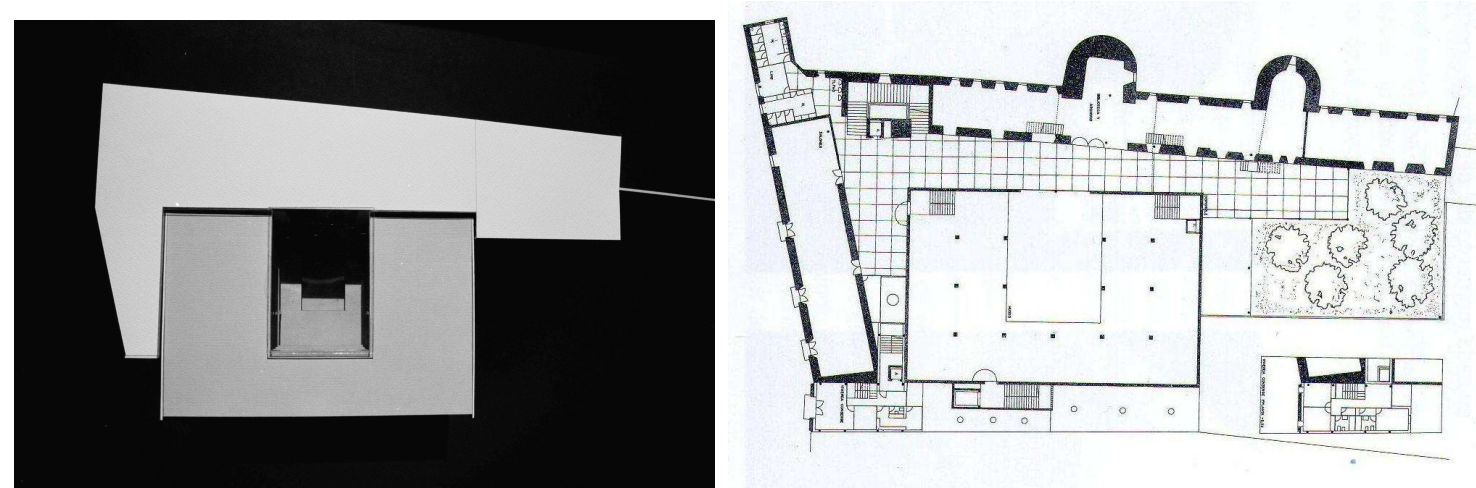

Figuras 5.1 y 5.2. El Museo 'insertado' en el viejo Palacio. Maqueta y planta.

Si bien es cierto que De la Sota sitúa la caja-museo en el centro de su propuesta, no es menos cierto que el verdadero espacio vertebrador del proyecto, aquel al que su autor dedica una mayor atención, está en el límite de ese centro, en el espacio intersticial que, como una prolongación de la calle, introduce la actividad urbana en el edificio (figuras 6.1 y 6.2). Ese vacío, cuidadosamente dimensionado y caracterizado, es el espacio capaz que insufla vida presente al interior, a la vez que recibe la luz procedente del espacio sagrado del Museo, aportando a esa vida presente aquella otra que reverbera en nosotros desde tiempos pasados. Todo el edificio es concebido, además, como un mirador privilegiado hacia la fachada sur de la Catedral, que se incorpora al Museo como su pieza más valiosa. El proyecto expresa así la voluntad de mostrar los hitos de la ciudad como los verdaderos bienes culturales, sobre los que el edificio-museo no hace sino llamar la atención del ciudadano. La forma visual del Museo es anodina -así se pretendió-, pero en absoluto lo es la idea profunda del proyecto. Esta actitud, que es la difícil, denota y requiere de un talento muy superior a la contraria -la que hubiera hecho primar lo vistoso sobre la trasgresión ideológica-. También es la más difícil de asumir por el político contemporáneo, que demanda imágenes exportables para incentivar la actividad turística, y no la auténticamente cultural, en torno al Museo. 
TEJEDOR FERNÁNDEZ, Luis (2012): "El centro histórico y el de nuestra propia historia. Sobre el Museo Provincial de León (Alejandro de la Sota)" [en línea]. En: Angulo Recto. Revista de estudios sobre la ciudad como espacio plural, vol. 4, núm. 2, pp. 75-84. En: http://www.ucm.es/info/ angulo/volumen/Volumen04-2/articulos05.htm. ISSN: 1989-4015
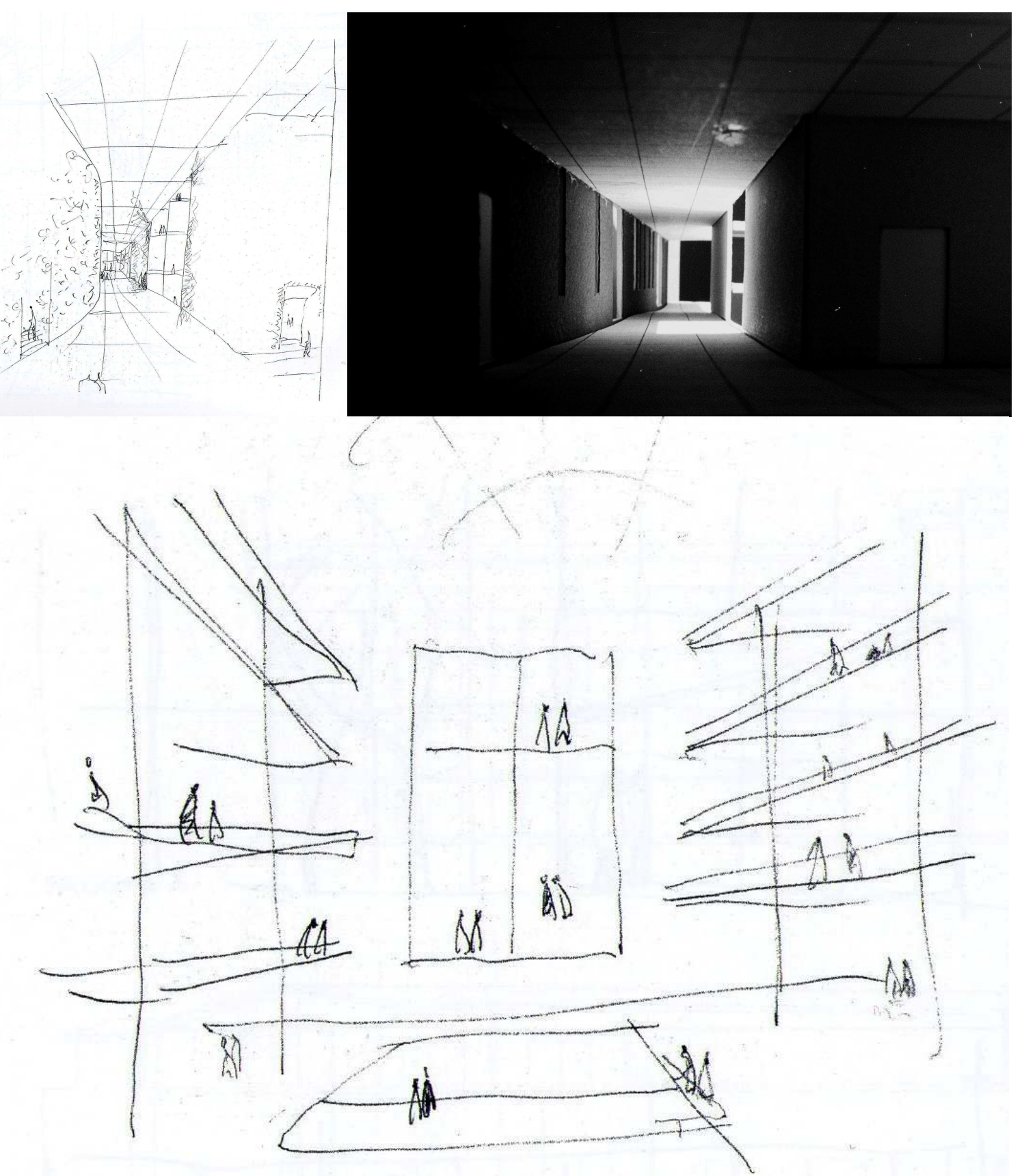

Figuras $6.1,6.2$ y 6.3. Dibujo y maqueta del intersticio entre el viejo Palacio y el nuevo Museo, y dibujo desde el interior del Museo mirando hacia el 'escaparate'.

Desde nuestro punto de vista, este proyecto otorga un valor cultural a los espacios urbanos que median entre los edificios, que trasciende el valor patrimonial de los propios edificios. 


\section{Conclusión}

A partir de la diferencia entre los conceptos de patrimonio y de bien cultural señalada por Italo Calvino, y del estudio de las características del proyecto del Museo de León de Alejandro de la Sota mostradas en el apartado anterior, podemos deducir las dificultades con las que suele toparse una determinada manera de hacer arquitectura fundamentada en el hecho mismo de habitar, primando en su formalización la vida sobre la mera apariencia, lo cultural sobre lo patrimonial.

\subsection{Coda: Centro y Cero}

Finalizaremos con una asociación mental, de un más que dudoso rigor etimológico, pero inevitable desde que hace poco leyéramos una reflexión de Louis Kahn narrada por el arquitecto hindú Charles Correa. Se trata del vínculo que puede existir entre los términos centro y cero. Ambos nos trasladan a un origen, sea este el de cualquier actividad que emprendamos, o al mismo origen de nuestra propia vida. Creemos que puede establecerse alguna relación entre lo que nos dice Kahn y las intuiciones que expresábamos al principio de este artículo, a propósito del carácter fundacional o regenerador de los edificios de Loos y Scharoun. Nos cuenta Correa:

Lo que Kahn solía decir a sus alumnos era algo así: "Amo la historia inglesa, amo su lado sangriento. Tengo ocho volúmenes y disfruto leyéndolos". Después de una pausa, añadía: "Bueno, en realidad no me he leído los ocho, solo el primero, y tampoco entero, solo las primeras páginas". Luego añadía: "En realidad, no creo que la historia empezara como dicen que empezó. Creo que empezó antes. iQuiero leer el volumen cero!". Y luego terminaba con esta frase verdaderamente extraordinaria: "la arquitectura es magnífica porque guarda relación con lo más recóndito de la mente, con lo que todavía no ha sido dicho y con lo que todavía no está hecho". (Correa 2008: 105).

En esta época que nos ha tocado vivir, confiemos en que tantas redefiniciones pendientes nos conduzcan a encontrar ese centro-cero, y que proyectos como el aquí expuesto no terminen "arrojados a la basura", siguiendo el que hasta ahora ha sido, según nos dice Calvino, el gesto instintivo del hombre -0 del políticocontemporáneo. Volvamos a viajar y dejemos de hacer turismo. 


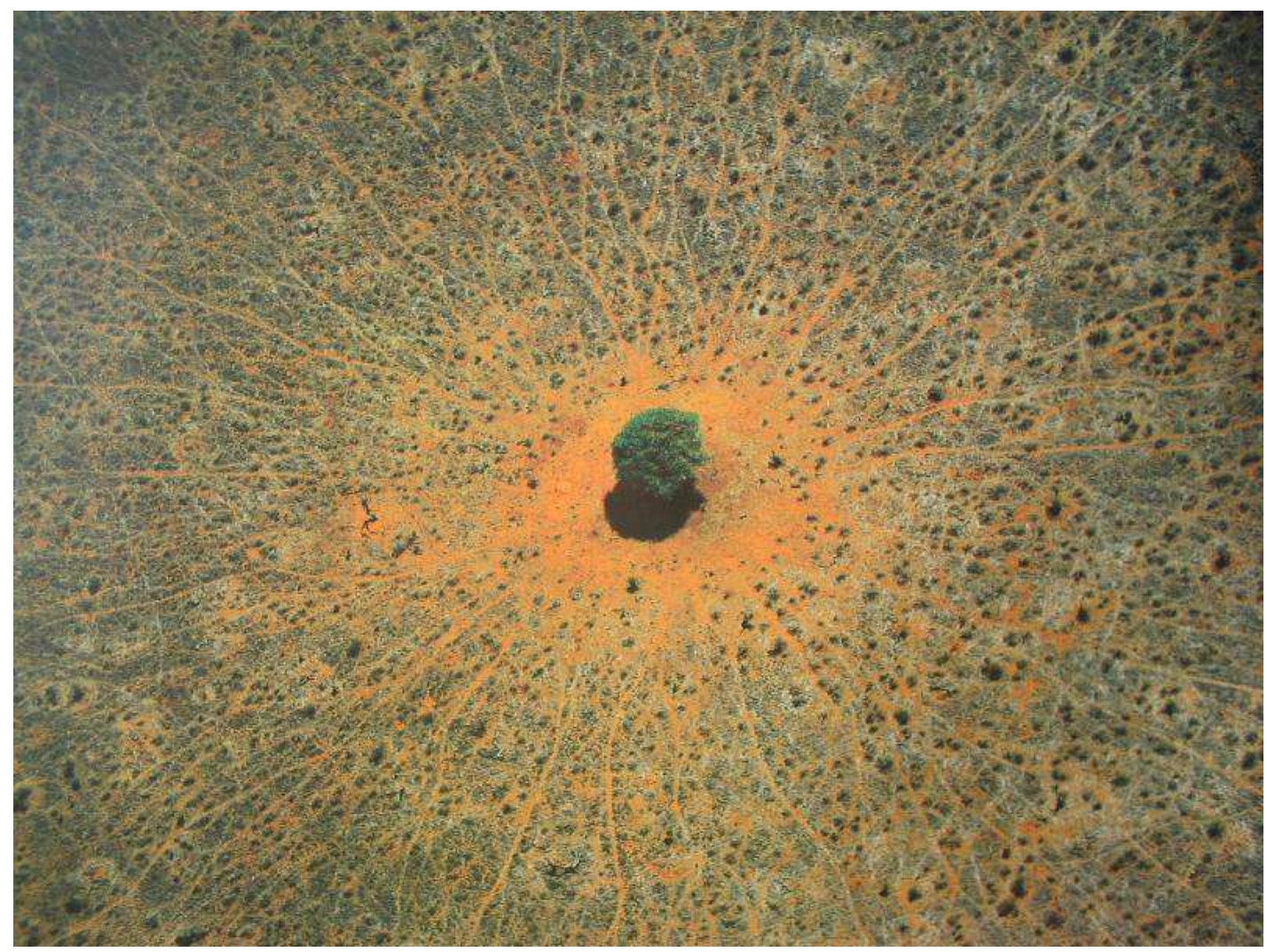

Figura 7. Acacia en Kenia: centro y cero.

\section{Bibliografía}

ÁBALOS, Iñaki; LLINÀS, Josep; y PUENTE, Moisés (eds.) (2009): "Museo Arqueológico Provincial. León, 1984", en Alejandro de la Sota, pp. 494-505. Barcelona: Fundación Caja de Arquitectos, col. Arquia/temas, núm. 28.

CALVINO, Italo (1998): "El patrimonio de los dragones", en Colección de arena, pp. 47-52. Madrid: Siruela.

CORREA, Charles (2008): "Cero", en Un lugar a la sombra, pp. 105-125. Barcelona: Fundación Caja de Arquitectos, col. La cimbra, núm. 5.

DE LA SOTA, Alejandro (1989): "Museo Provincial, León, 1984", en Alejandro de la Sota, arquitecto, pp. 190-197. Madrid: Pronaos, primera edición.

JARAUTA, Francisco (1998): "¿Qué pasó con Ulises?", en Mundialización y conflictos civilizatorios. Murcia: Foro de los noventa.

LAHUERTA, Juan José; y PIZZA, Antonio (eds.) (1985): Alejandro de la Sota, arquitecto. Catálogo de la exposición celebrada en mayo y junio de 1985 en Barcelona. Barcelona: CRC Galería de Arquitectura y Col-legi d'Arquitectes de Tarragona.

NORBERG-SCHULZ, Christian (1979): Architettura occidentale. Architettura come storia di forme significative. Milán: Electa, primera edición. (Trad. española: Arquitectura occidental, Barcelona, Gustavo Gili, col. GG Reprints, 1999, tercera edición.

PUENTE, Moisés (ed.) (2002): "León y Zaragoza. Barcelona, 1988", en Alejandro de la Sota. Escritos, conversaciones, conferencias, pp. 187202. Barcelona: Gustavo Gili. 